DOI: https://doi.org/10.35560/jcofarts95/35-48

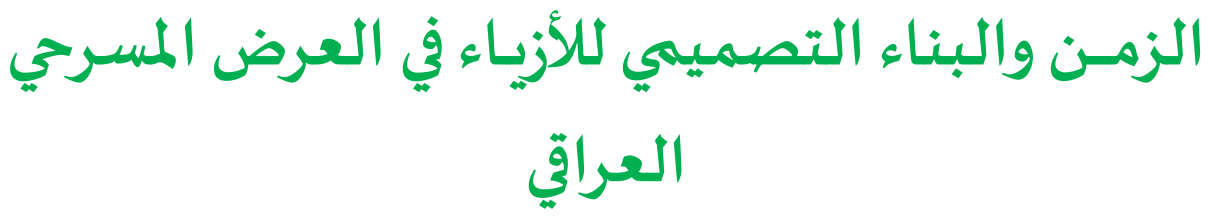

1 محمود جبـاري حسافظ 1 محس ISSN(Online) 2523-2029, ISSN(Print) 1819-5229 مجلة الأكاديمي-العدد 95-السنة 2020

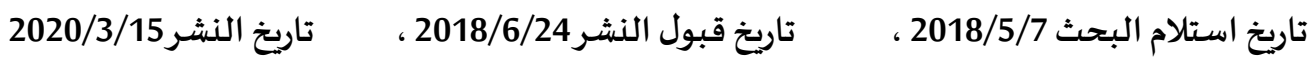
(c) (†) This work is licensed under a Creative Commons Attribution 4.0 International License ملخص البحث يشكل الزي المسرحي مع بقية عناصر العرض المسرحي منظومة من العلاقات الدلالية تنتج عنها صورة

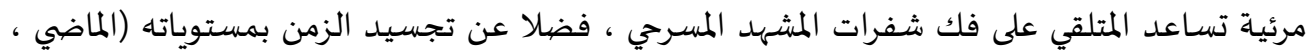

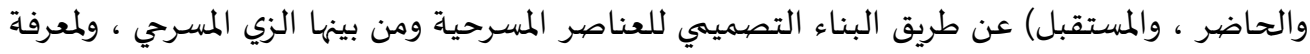

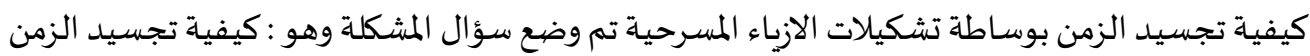

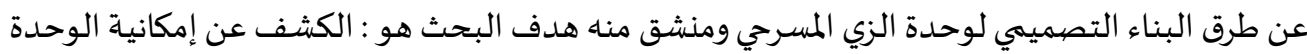

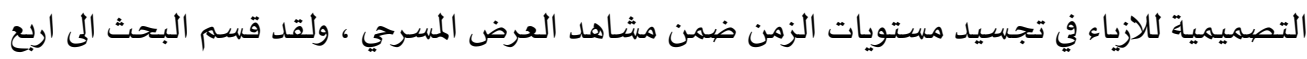

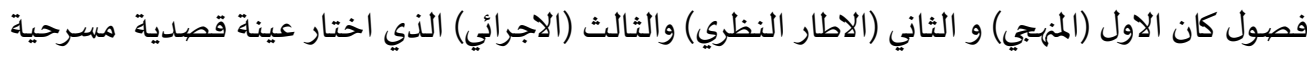

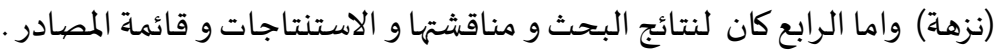
الكلمات المفتاحية: الزمـن ، الأزيـاء. الإطار المنه-جي أولا_مشكلة البحث والحاجة إليه: أن الفنون المسرحية ذات صبغة جمالية متميزة وتجربة تفاعلية مابين الفنان والمتلقي وهذا ما جعلها

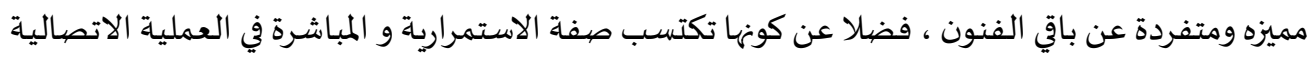
(البصرية ، و السمعية ، و الحسية الجمالية ) ما بين الممثلين وهم مرتدين أزيائهم وملحقاتهم وهئه وهيئاتهم

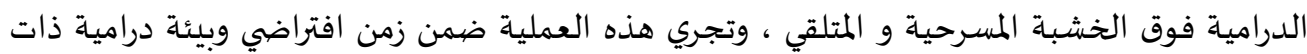

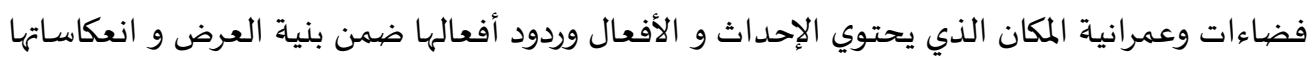
الفكرية و التأويلية و الفلسفية والحسية الجمالية على حالات التلقي و تفسيراتها .

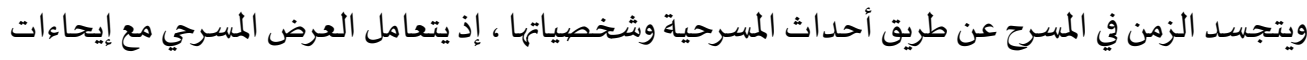

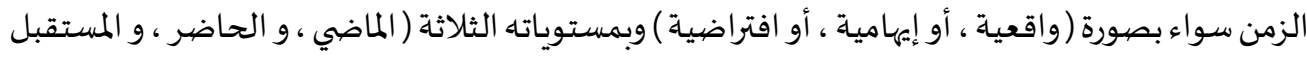

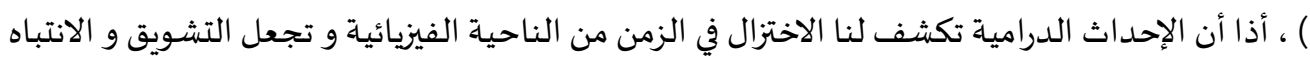

1 أستاذ مساعد دكتور/كلية الفنون الجميلة/جامعة بغداد، dr.mahmood@avic.uobaghdad.edu.iq 
محمود جباري حسافظ

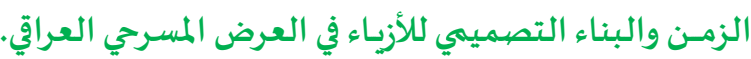

ISSN(Online) 2523-2029, ISSN(Print) 1819-5229 2020 مجلة الأكاديمي-العدد 95-السناء العنصران الملازمان للمشهد المسرحي ، أذا تحمل الإحداث زمنا قد يكون بعيدا في أزمنة سحيقة تكون حاضرة

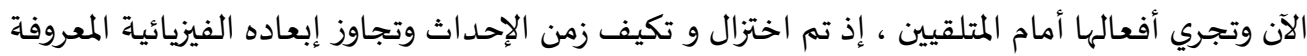

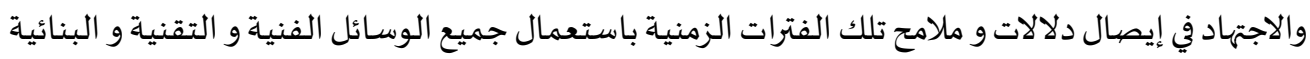

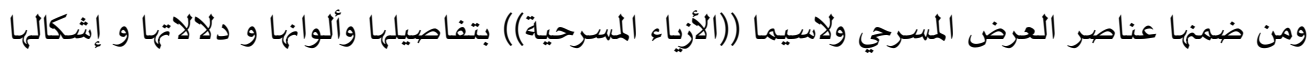

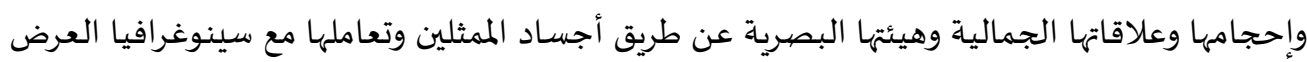
المسرحي ضمن العملية البصرية و البنائية و التركيبية و الجمالية .

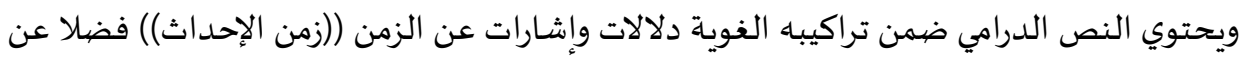

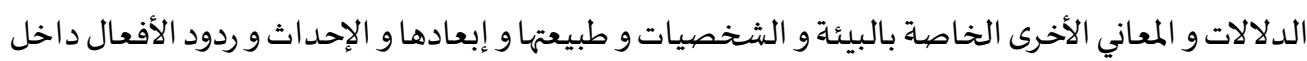
بنية النص الدرامي ، وكلما كانت إبداعات المؤلف عالية ازدادت الإحداث ومعانيها تشويقا و جمالا ويصبيح

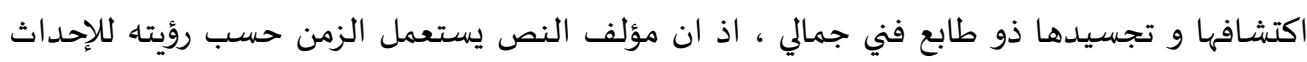

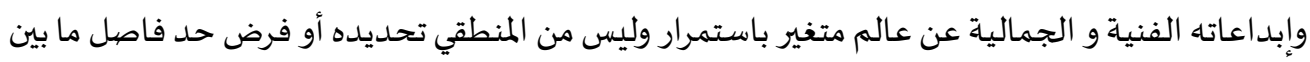

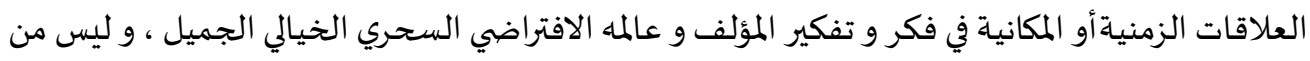

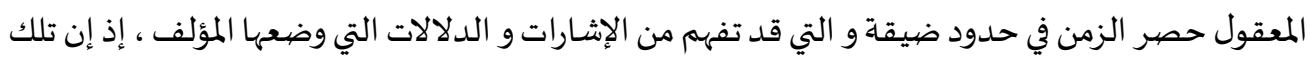
التلميحات هي للدلالة عن بعض الإيحاءات بالإحداث بشكل عام وان الزمن في فكر المؤلف خاضع لمن لاعتبارات

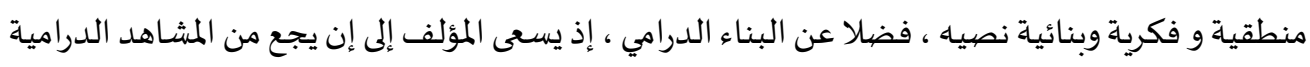

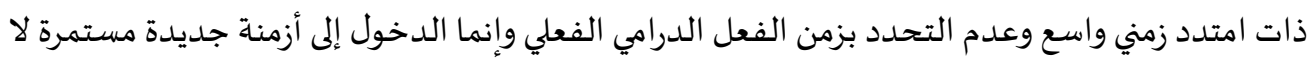

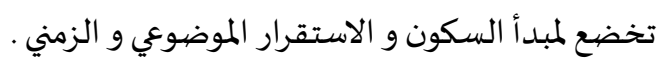

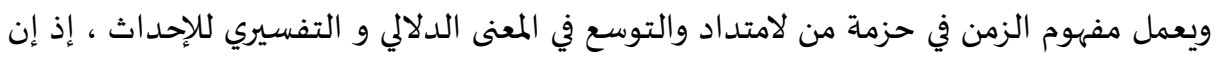

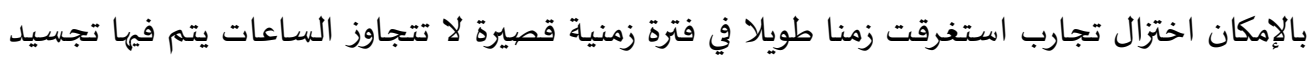

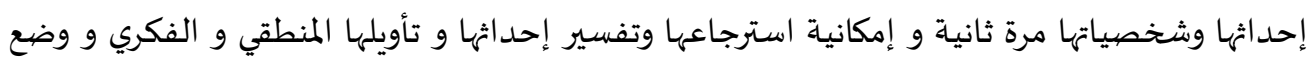

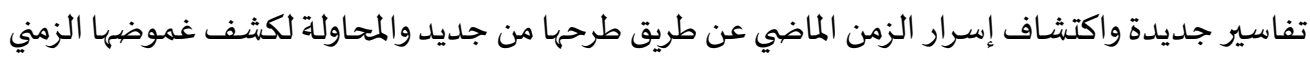

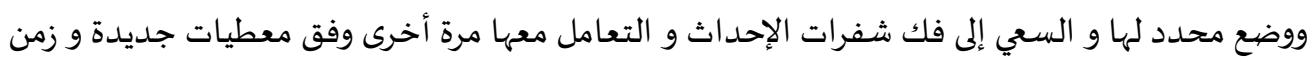

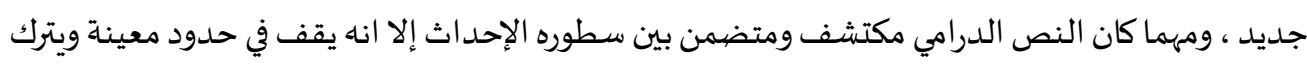

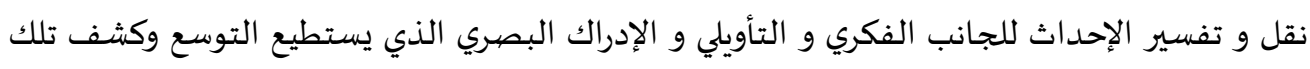

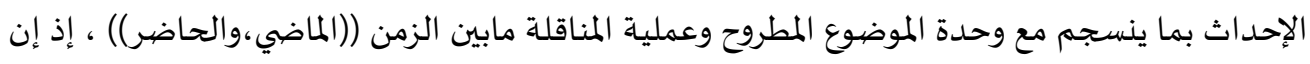

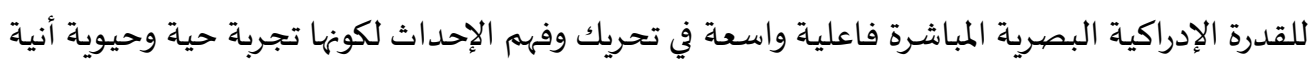

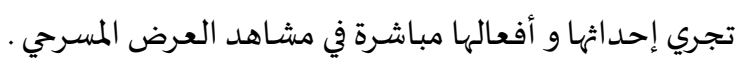

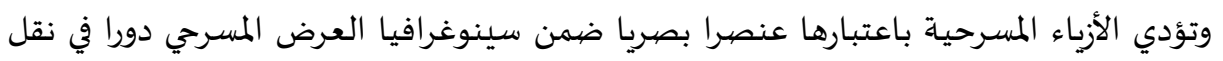

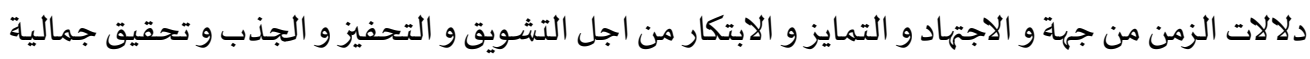

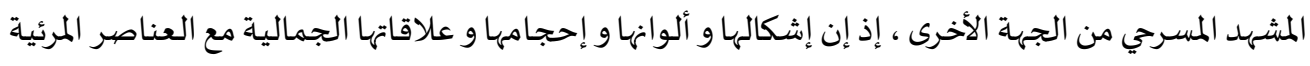

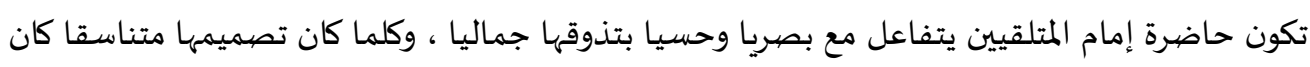


محمود جباري حسافظ

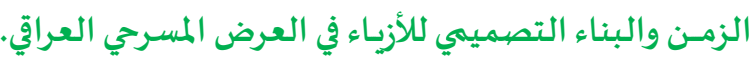

ISSN(Online) 2523-2029, ISSN(Print) 1819-5229 2020 مجلة الأكاديمي-العدد 95-السناءينة إدراكها واضحا وهذا لا يعني عدم المحافظة على وحدة الموضوع و الحدث الزمني وإنما الرغبة في الاستمرارية و التشويق في عملية التلقي .

والهدف منها خلق حالة من التفاعل ما بين مكونات العملية الاتصالية ، إذ إن طرح موضيوعات تاريخية

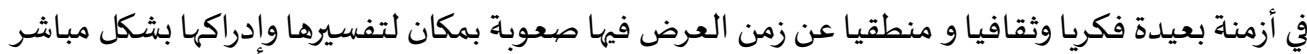

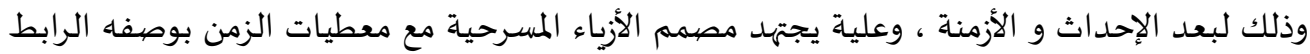

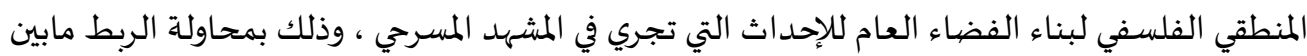

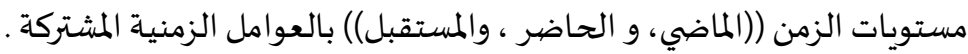
وبناء على ما تقدم يمكن طرح تساؤل مشكلة البحث كما يأتي :

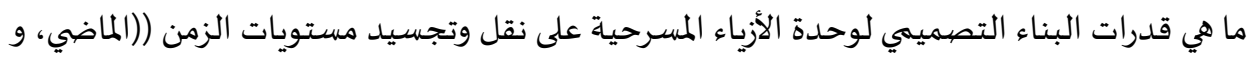

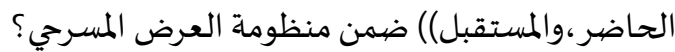

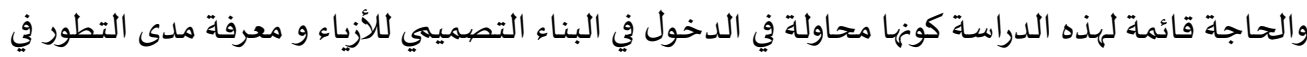

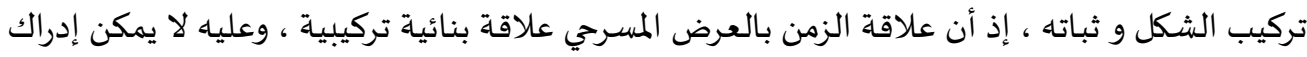

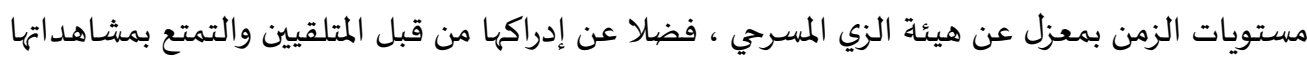

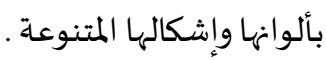
ثانيا _ أهمية البحث : تتجلى أهمية البحث الحالي في معرفة مستويات الزمن المسرحي الافتراضي

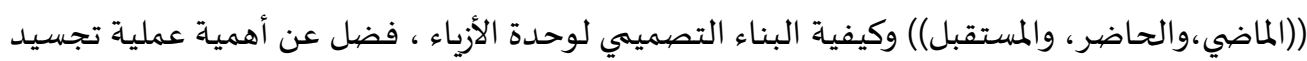
الزمن عن طريق إشكال الأزياء و بقية عناصر العرض المسرحي ،وأيضا للبحث أهمية كونه يساهم في تحفيز مصممي الأزياء المسرحية و معرفتهم بدلالات الزمن التي تستطيع وحدة الأزياء حملها بين تشكيلاتها ، وإدراك

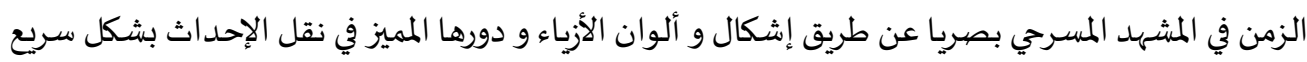
و ، و مباشر عن طريق رؤيتهاو التفاعل معها بصريا في عملية التلقي ، كما يفيد البحث الجهات البهاء الرسمية :

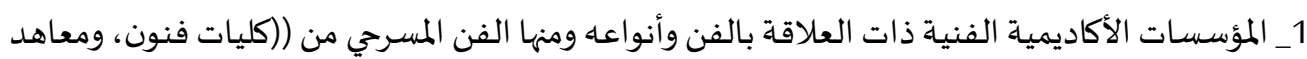
فنون ، والمدارس الخاصة بالفن المسرحي )) .

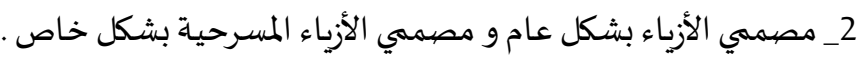

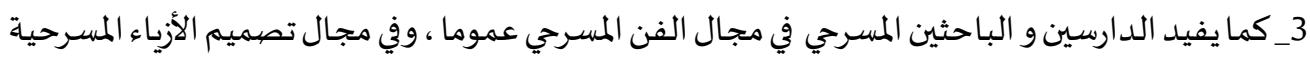
خصوصا . 4_ كما يفيد جميع المتابعين و المهتمين بالفنون الجميلة والفنون تصميم الزي المسرحي .

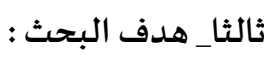

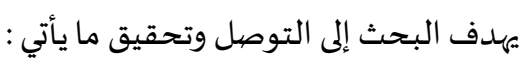
الكشف عن إمكانيات الوحدة التصميمية للأزياء المسرحية في تجسيد مستويات الزمن ((الماضي ، والحاضر ماضير

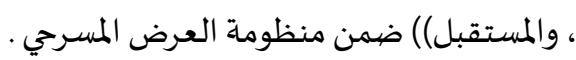
رابعا__حدود البحث : 1_ الحدود الموضوعية : دراسـة وتحليل نماذج من تصاميم أزياء مسرحية في العرض المسرحي العراقي . 
محمود جباري حسافظ الزمـن والبناء التصهميمي للأزيـاء في العرض المسرحي العراقي..

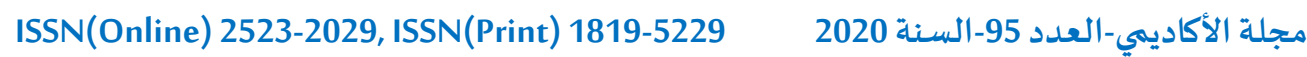
2_ الحدود المكانية : يتحدد البحث مكانيا في العراق/مدينة بغداد/ المسارح ضمن الرقعة الجغرافية لمدينة بغداد ((العاصمة)) )

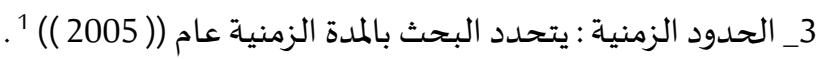
خامسا__تحديد المصطلحات : 1 1

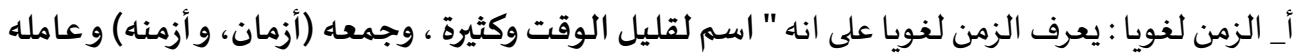
(مزامنة) في الزمن كما يقال مشاهرة من الشهر") أزمنه) و وعامله (مزامنة) في (AL_Razi,1982,257).

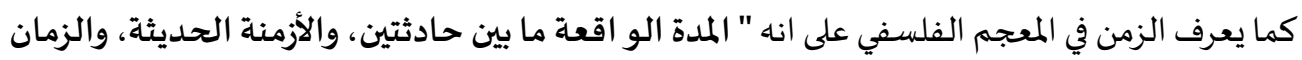

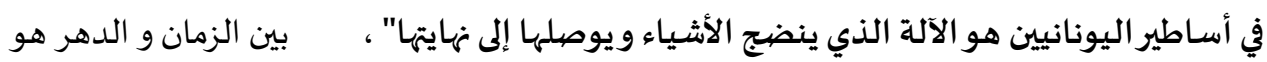

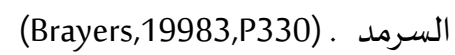

ب_ الزمن مفهوما: يعرف الزمن على انه " زمن الدال بعد زمني الدال خبر ، مثال: يمكن الحديث عن سنة

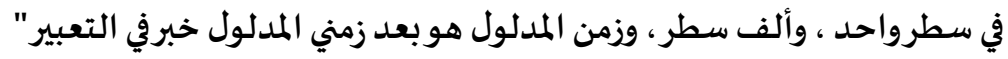

(Brayers,1985,B:255) وأيضا الزمن هو " الظاهرة الغالبة على معاني الزمان ، أنها تعكس صدى العصر و صورته في ملامح "إدراكية " وانين

(King,1991,B,19) وألزمنه هو" مدة قابلة للقسمة ، وهو صفة تطلق على الوقت ((القليل أو الكثير))، والزمن هو الوقت

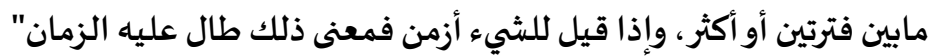

(AL-Sayegh,2000,B:45) وكما أن الزمن هو " المدة المعنوية التي يتشكل منها أطاركل حياة وحيزكل فعل ولكل حركة ، وإنها ليست

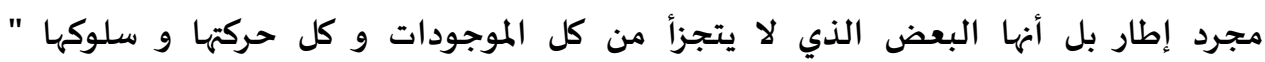
(AL_Zayed,1988,P.7) ويمكن وضع تقسيم لزمن وهو " الأول:يتألف الزمن من ماضي ، وحاضر ، ومستقبل) والثاني : الزمن من

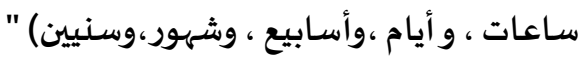

(AL_Shahan,1982,B:12) د_ التعريف الإجرائي للزمن : بناء على ما سبق يمكن اعتماد تعريف((الصائخ)) للزمن وعده تعريفا إجرائيا للبحث الحالي لما له من أهمية

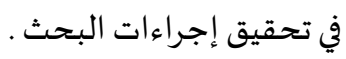

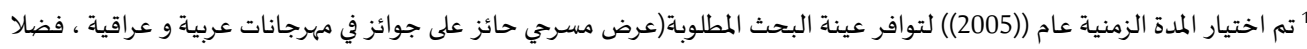

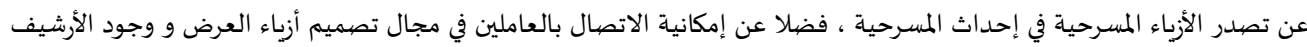
الصوري لشخصيات العرض المسرحي. 


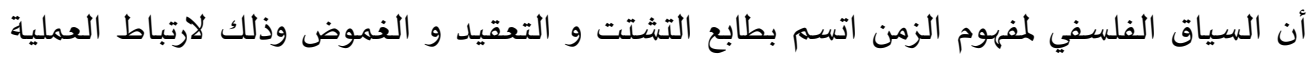

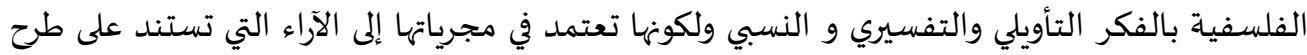

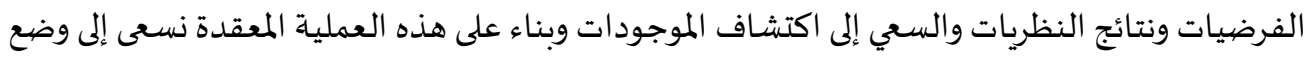

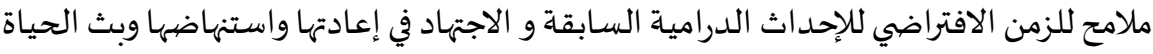

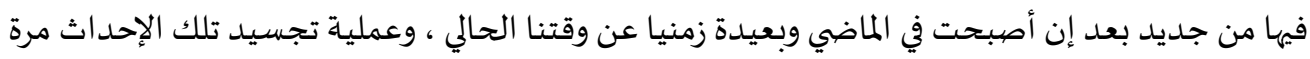

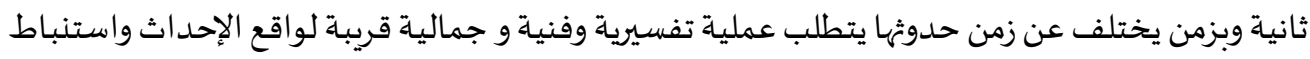

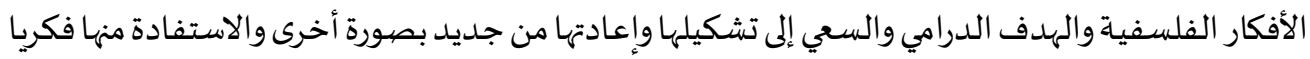
وفلسفيا وجماليا .

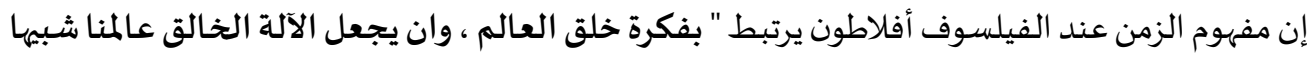

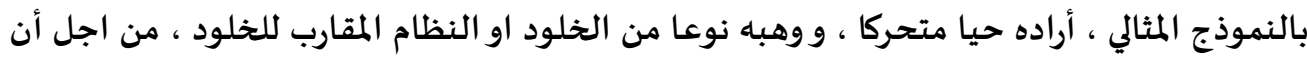

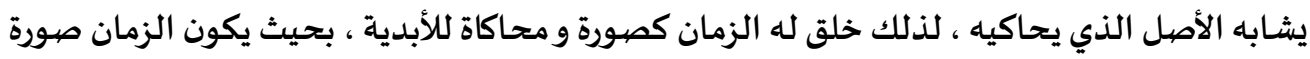

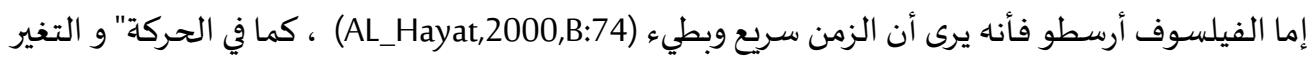

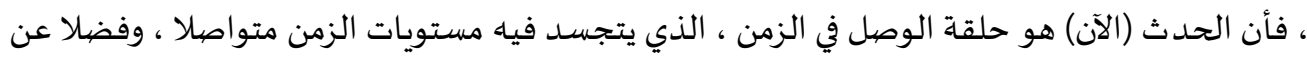

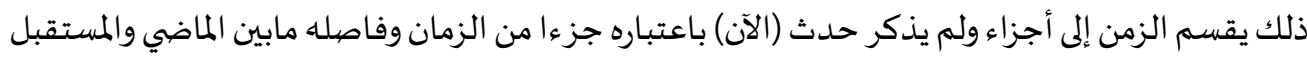

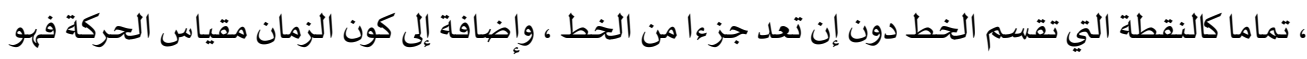

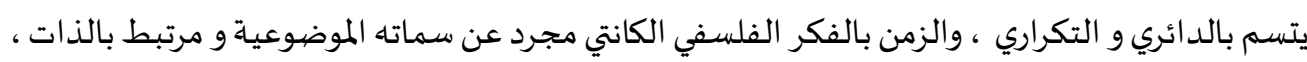

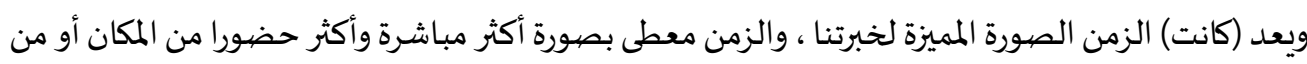

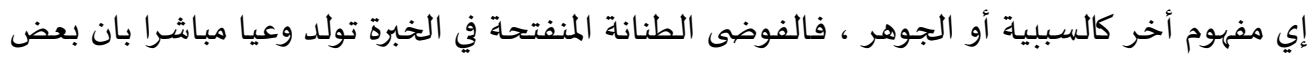

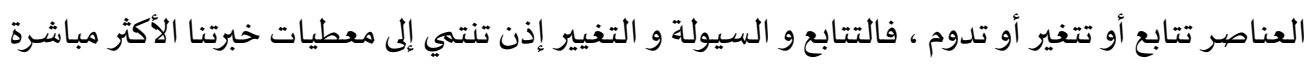

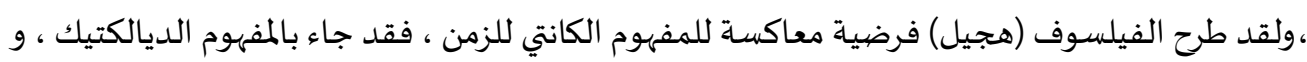

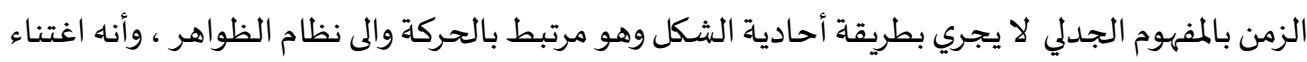

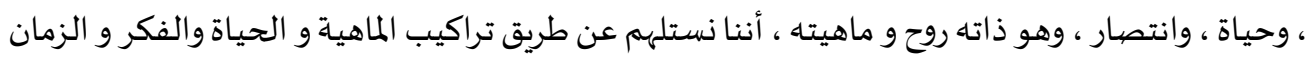

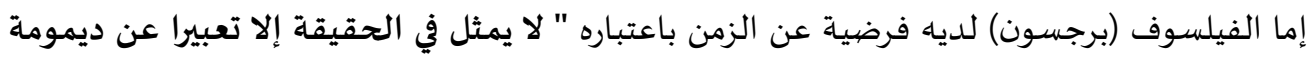

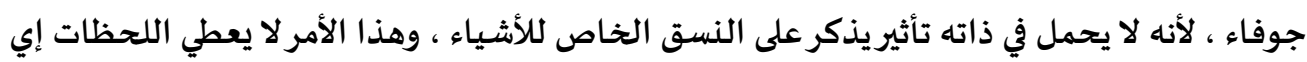

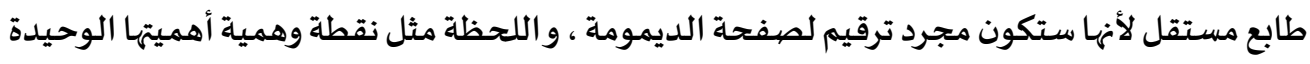

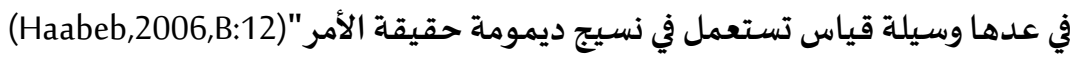

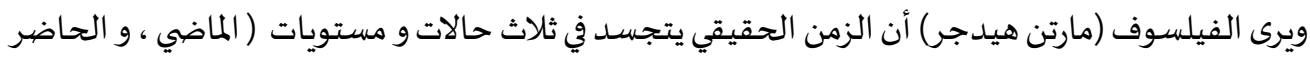

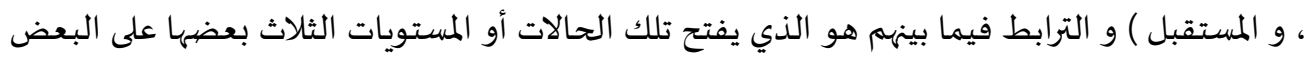

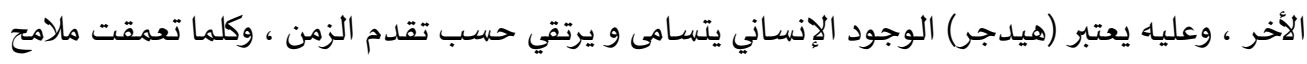


محمود جباري حسافظ

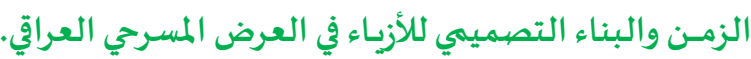

ISSN(Online) 2523-2029, ISSN(Print) 1819-5229 2020 مجلة الأكاديمي-العدد 95-السناء الزمن في دواخلنا ، فحركة الزمن هي تمثيل لما نشعر فيه و لا يمكن وضع محدد لها أو تحديدها بحدود فاصلها و معروفة لأنها مستمرة بالحركة و التجديد باستمرار (ph:Ghazwan,2000,B:12)

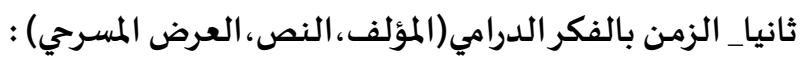

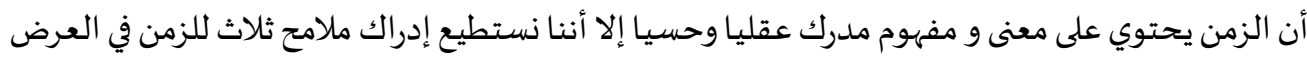

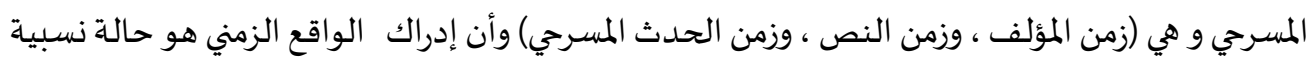

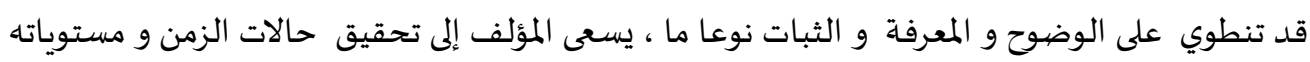

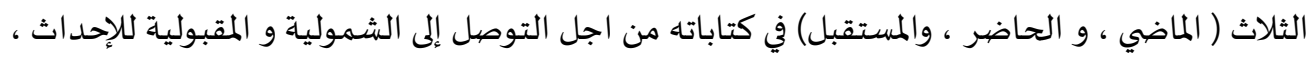

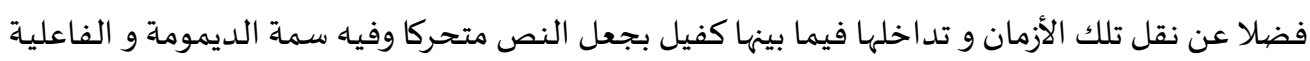
فالنص الدرامي الأكثر مقبولة هو ذلك النص المنفتح زمنيا وفيه قوة الفاعلية وليس نصا جامدا مغلق زمنيا

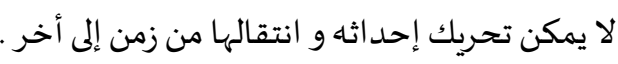

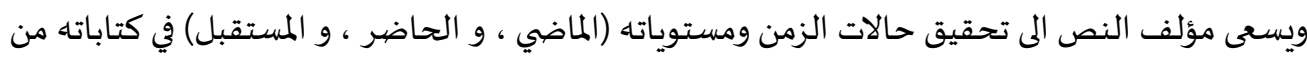
اجل تحقيق الشمولية والمقبولية لزمن الحدث فضلا عن نقل تلك الازمنة من من مستوالاتها الماضي وجعلها

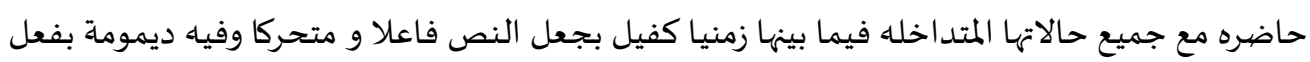

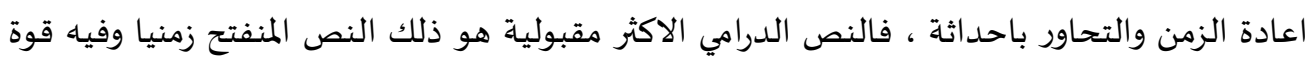

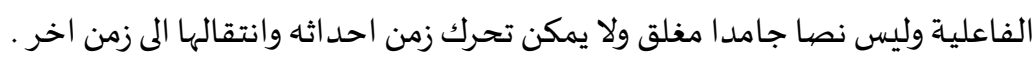

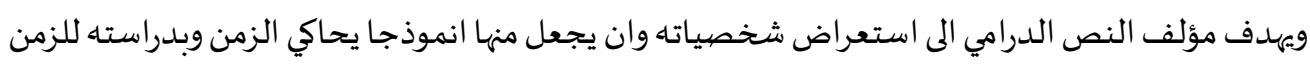
كحالة تاريخية يستطيع تحديد تاريخ الفعل بدقة كبيرة بالاعتماد على التفسير الزماني و المكاني و النفسي

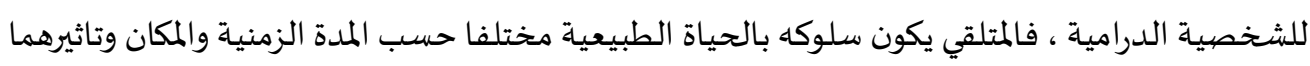

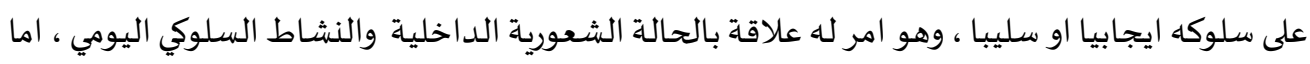

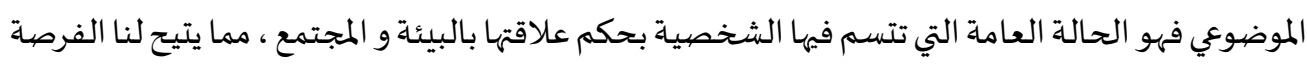

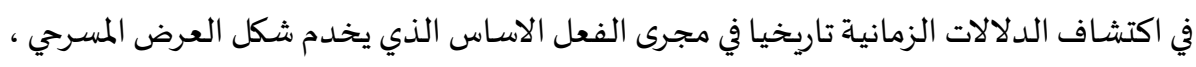

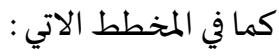
مباشر دلالة زمنية ـ نفسي (سلوكي) ـ ذاتي غير مباشر دلالة زمنية ـ موضيوعي ـ قياسي مني أن هناك " داخل نص المسرحية مولدات نصية (للعرضية) ، و انه يمكن تحليل النص المسرحي بناء على فيلى

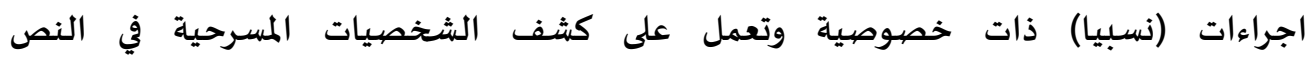
(AL_Zayaed,1993,B:4) ويعد الزمن بالعرض المسرحي ركن اساسي باحداثه باعتبار العرض المسرحي "ظاهرة فنية تخضع بكليتها

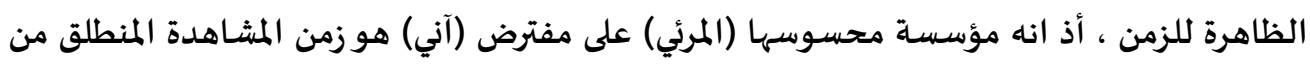


محمود جباري حسافظ

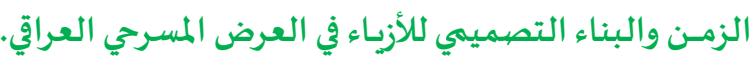

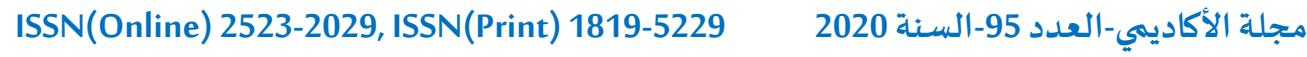
نقطة مفترضة على خشبة المسرح ، وزمن العرض لحظة (آن) متعال على كل الأزمان ، "كاشفا عن شبكة علاقات زمنية جديدة. (Mahade,1996,B:19)

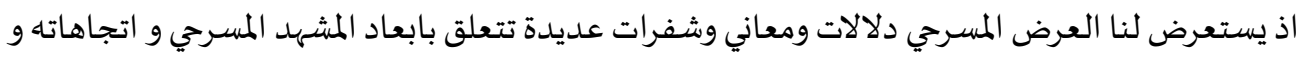

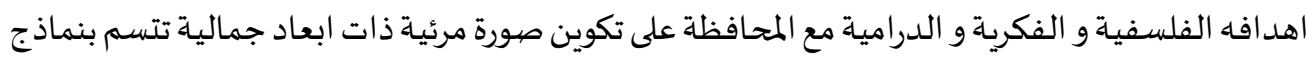
ابداعية مبتكرة ،و يسعى العرض المسرحي على تحريك الافكار المترسبة و المفاهيم السابقة واعادة استنهاضهيا

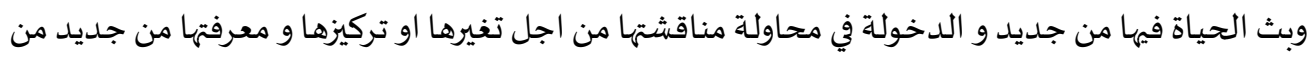

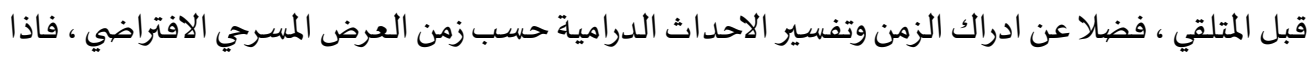

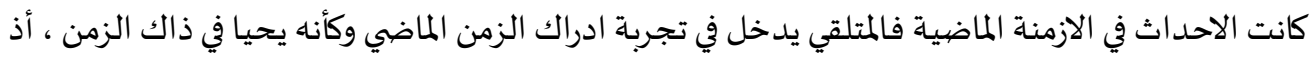

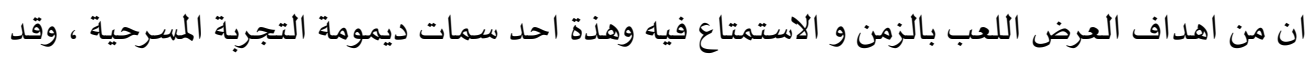
تظهر حالة التناقض و الاختلاف في بنيه عرض مسرحي عن الآخر تبعا للاختلاف بالتأويل وتفسير زمن الاحداث. وتسعى التجربة المسرحية الى محاكاة زمن فعل الشخصية في النص الذي هو في زمن الماضي و نجسده في زمن الفعل في العرض المسرحي (الحاضر او الآن) بشرط ان ينتج الفرصة و المجال مفتوح امام المتلقي لاستقبال

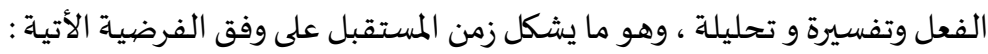
زمن الفعل ـ النص ـ الماضي

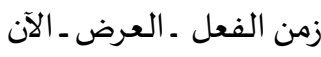

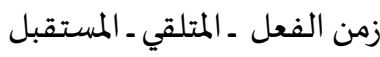

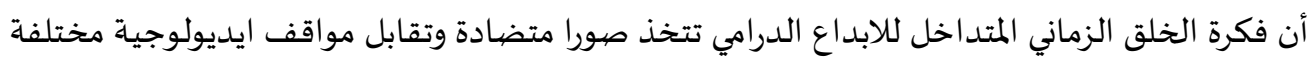

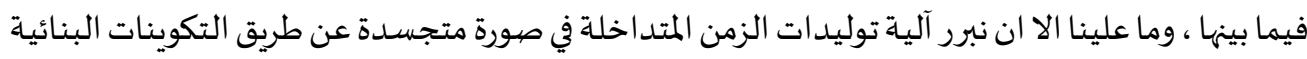
بالعرض المسرحي التي تعبر عن الزمن و حالاته و مستوياته . ان فضاء العرض المسرحي لا يمكن ان يوجد نفسـه الا بوجود فضياء النص ، فأن فضياء الأخير يبقى منقوصيا

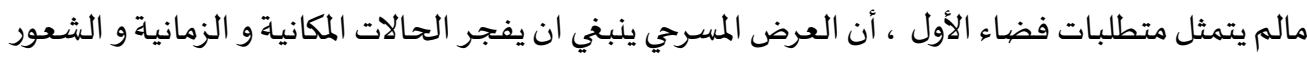
فيها و التي قد وفرها المؤلف في لغة النص ، اي ان يعمل العرض المسرحي على وضع تصور زماني و مكاني

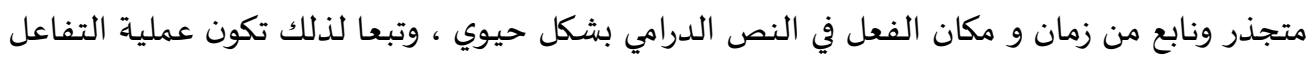

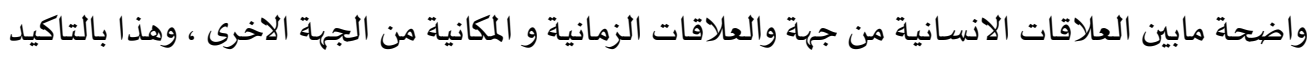

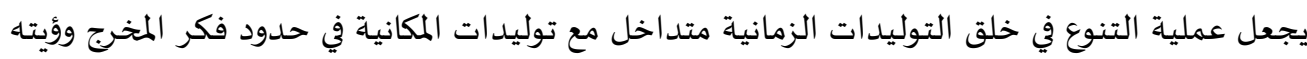
الجمالية .

ثالثا _تماثل الزمن بوساطة الزي المسرحي : الزماء تتماثل الازياء المسرحية لدى المتلقي بشكل مرئي و مباشر فضلاتلا عن تماثلها الذهني والفكري ومرجعياتها

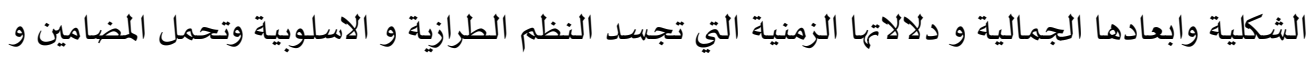

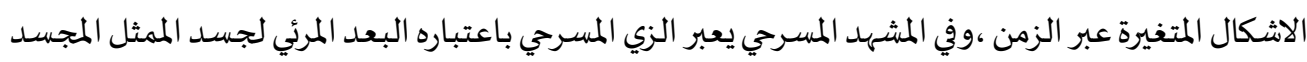

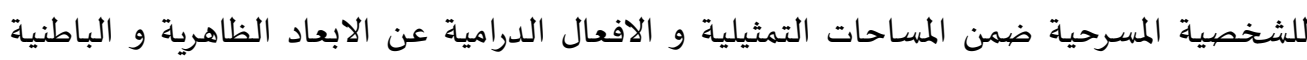


محمود جباري حسافظ الزمـن والبناء التصهميمي للأزيـاء في العرض المسرحي العراقي..

ISSN(Online) 2523-2029, ISSN(Print) 1819-5229 2020 مجلة الأكاديمي-العدد 95-السناء (الداخل،والخارج) لمفاهيم فكرة العرض المسرحي ، اذ يعد الزي وسيلة من الوسائل التي يستعين بها العرض

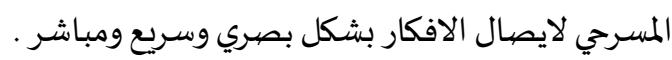

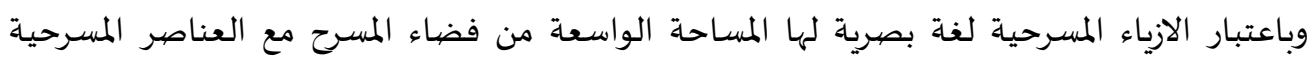

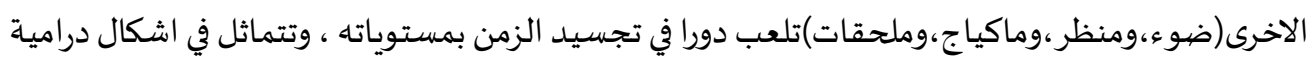

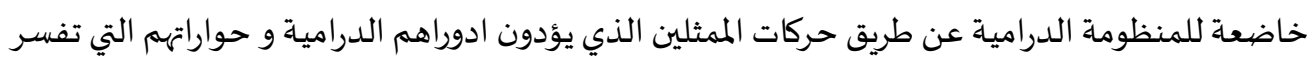

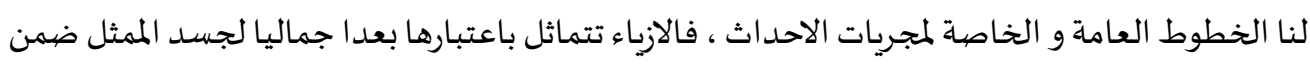

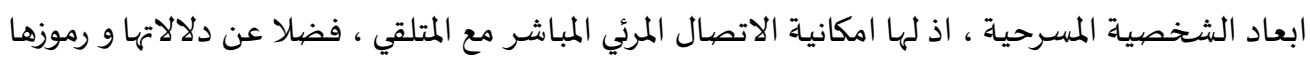

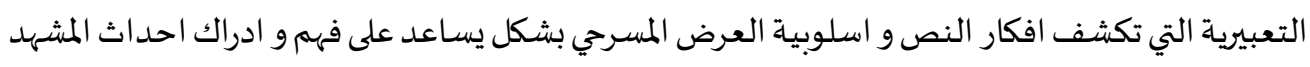

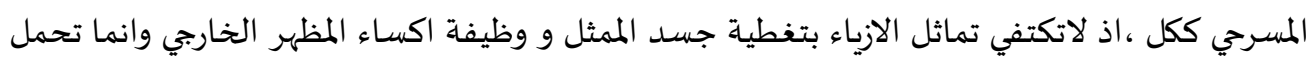

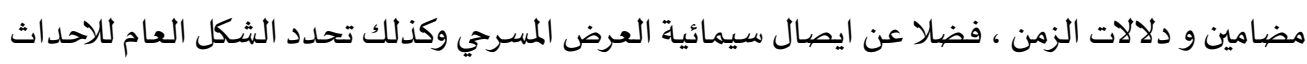

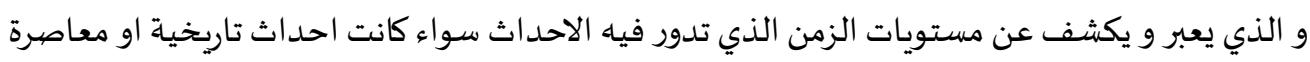

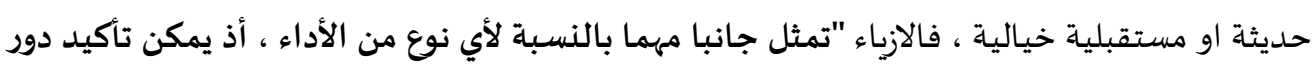

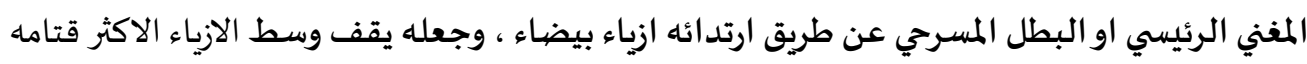

الخاصة بالشخصيات الاخرى(Maratn,1996,B:56)

، ويجتهد مصمم الزي المسرحي في البحث عن تفاصيل دقيقة من خلال الزمن وكذلك يسعى الى اكتشاف

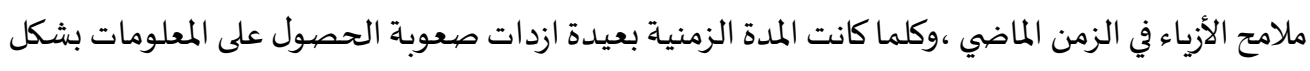
واضح عن اشكال وانواع الازياء في تلك الفترة الزمنية ، ويستعمل المصيمم خياله في تصيميم ازياء تتسم بالتجديد و الابداع و الحداثة حتى لو كانت فيها اجزاء تصميميه تشير دلاليا الى زمن الماضي او مدة زمنية معينة . بالت

أن عملية اخراج تصاميم تعود شكليا الى الزمن الماضي وتجسـد في الزمن الحالي بحاجه الى المعرفه التقنية

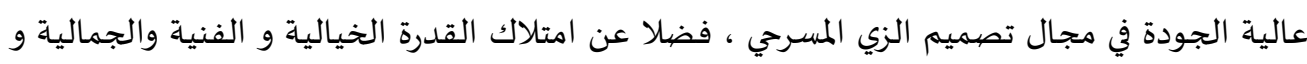

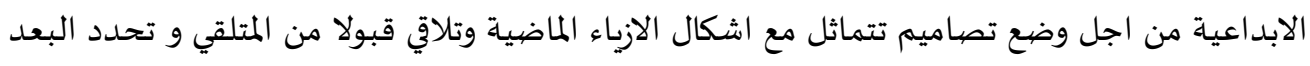

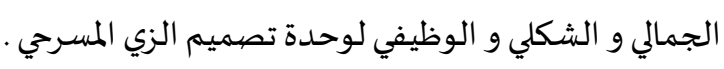

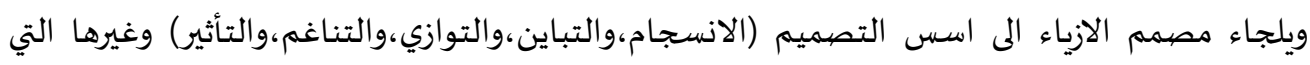
تستعمل في الوحدة التصميمية تبعا الى فلسفة واسلوبية المصيمم ، فضلا عن تأثير العوامل و السمات التي يسعى فيها مصيمم الزي المسرحي أن يضع افكاره ويطلق خياله من اجل تحقيق تصهيما يحافظ على الملامح

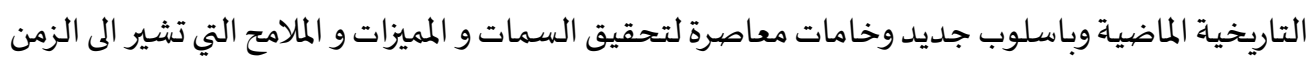

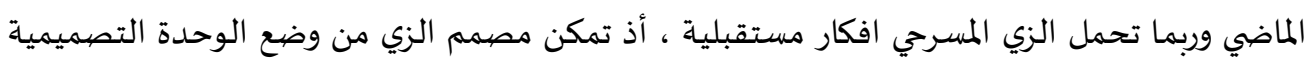

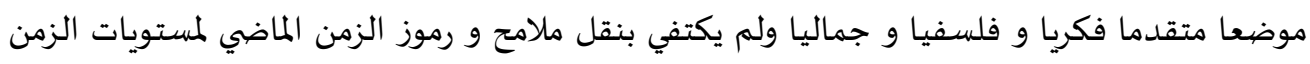

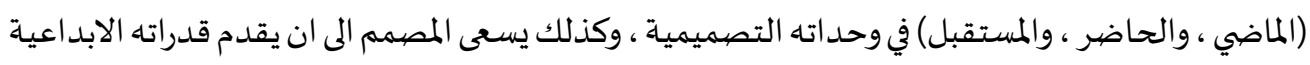

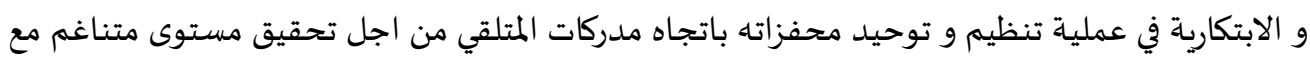

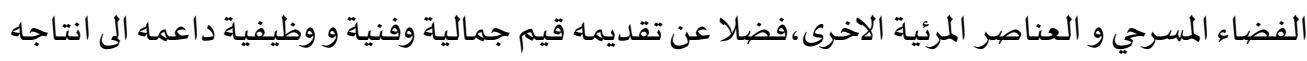


محمود جباري حافظ

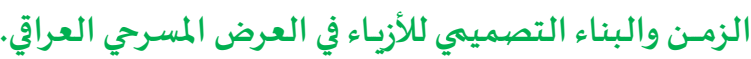

ISSN(Online) 2523-2029, ISSN(Print) 1819-5229 2020 مجلة الأكاديمي-العدد 95-السناء التصيميهي ، وعليه تكون الوحدة التصيميمية هي معطى جمالي بحد ذاته، اذ يمكن تحقيق الوحدة الموضيوعية

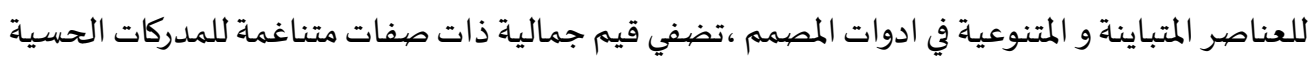

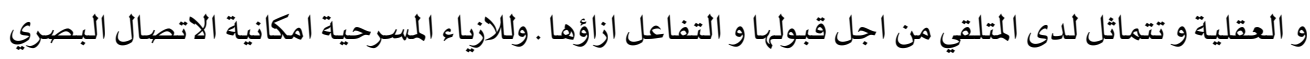

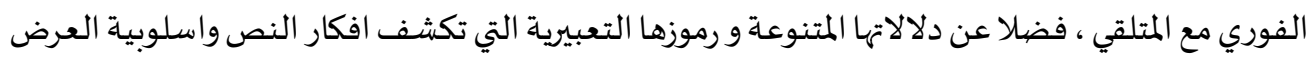

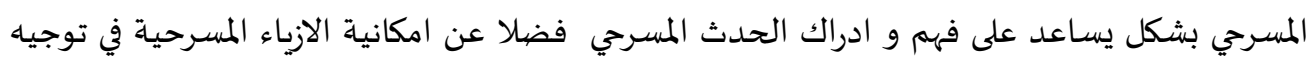

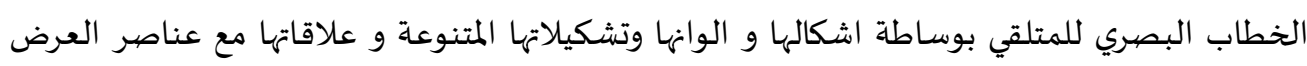

$$
\text { رابعا_الدراسـات السابقة : الاخرى. }
$$

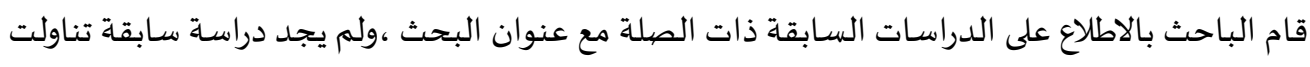

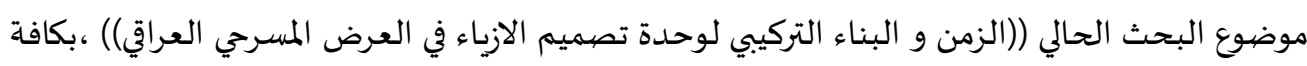
فصولة. خامسا_ مؤشرات الاطار النظري :

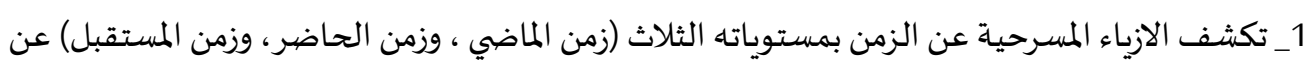
طريق الرمز الدلالي لوحداتها التصيميمية . لمسئ.

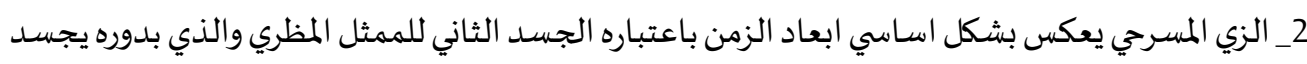
الشخصية المسرحية . 3_تحدد الازياء المدة الزمنية (الدقة التاريخية) عن طريق نقل الملامح الماضية لاشكال الزي من خلال وحد اتها

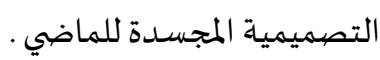
4_للحدث المسرحي القدرة على ايصال مستويات الزمن الثلاث وتبعا لذلك يحمل الزي المسرحي اشكال الزمن ضيمن الحدث المسرحي . 5_ أن دلالات الازياء و اشكالها من شأنها ان تحقق التماثل عند المتلقي سواء كان تماثل ذهني او فكري .

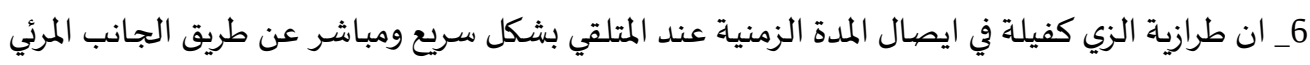

$$
\text { فوق خشبة المسرح . }
$$

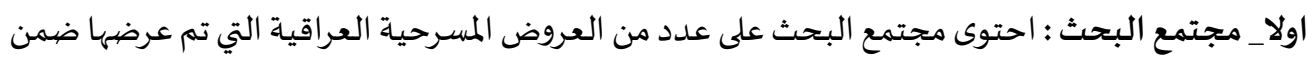

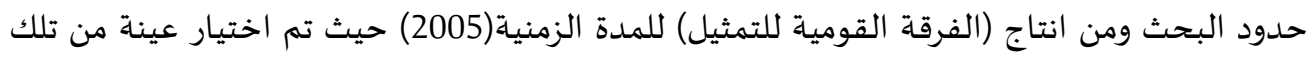
العروض . مان. ثانيا_منهج البحث : تم اختيار المنهج الوصفي التحليلي في مجريات البحث الحالي . 
محمـود جباري حسافظ الزمـن والبناء التصهميمي للأزيـاء في العرض المسرحي العراقي.. ISSN(Online) 2523-2029, ISSN(Print) 1819-5229 2020 مجلة الأكاديمي-العدد 95-السناءئة ثالثا_ عينة البحث : انسجاما مع هدف البحث و من اجل استخراج نتائج تخدم البحث الحالي تم اختيار

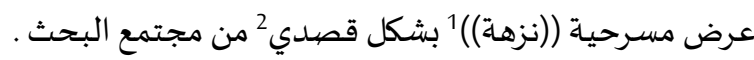

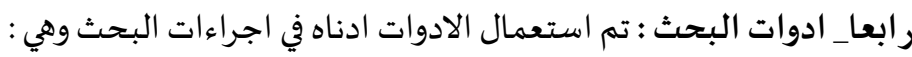

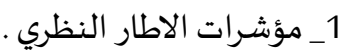

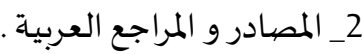
3_ القراص الليزرية للعينة . 4_الصور الفوتوغرافية . 5_الخبرة التحليلية للباحث.

خامسا_تحليل العينة : مسرحية ((نزهة)) تتلخص حكاية عرض مسرحية((نزهة)) حول زوجين اسماهما(الزوجة بيث،والزوج داف) يعيشان في زمن

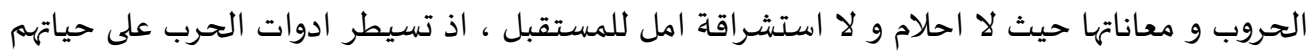

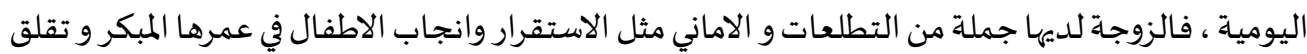

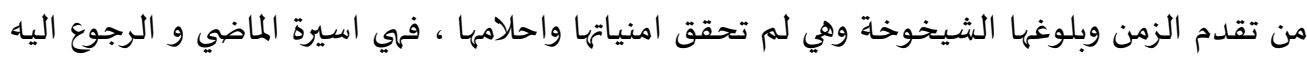

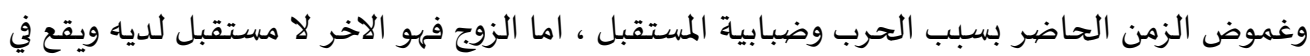

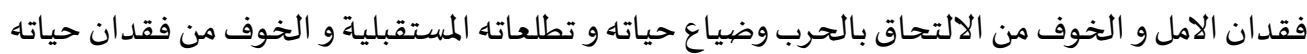

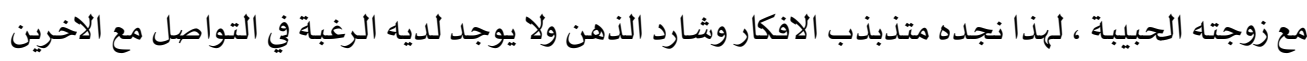

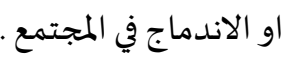
أن جماليات عرض مسرحية((نزهة)) ظهرت عن طريق الانسجام مابين عناصر العرض المرئية و التي خلقت

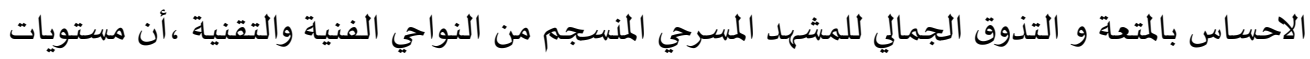

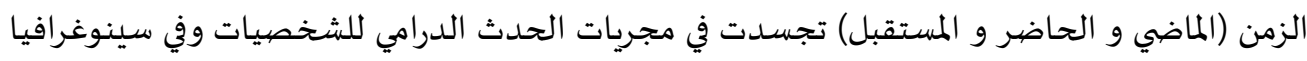

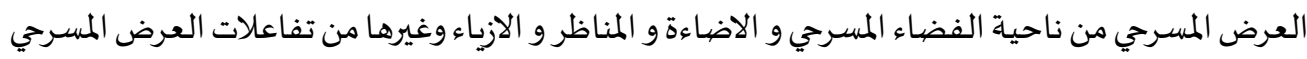
من اداء تمثيلي و تجسيد الشخصيات بشكل جمالي و فني .

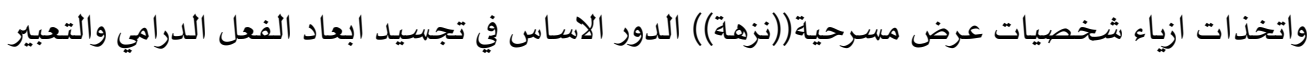

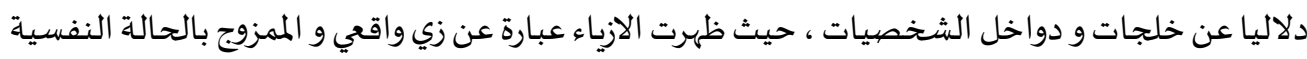

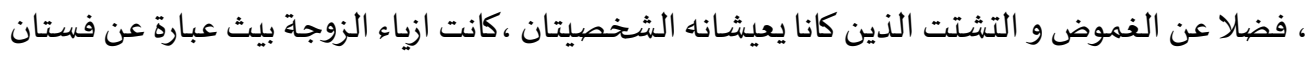
ابيض قصير نقشت عليه نقوش نباتيه و هندسية واضحة باللون الاسود ،ليعبر عن التبادلية مابين اللونيين

1 عرض مسرحية((نزهة)): اعداد واخراج احمد حسن موسى، انتاج الفرقة القومية العراقية للتمثيل،عرضت على المسرح الوطني في مدينة

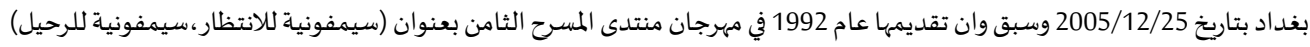

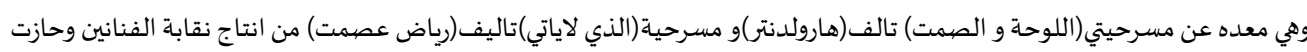

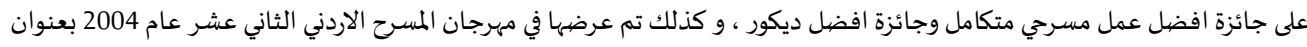

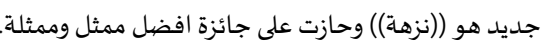

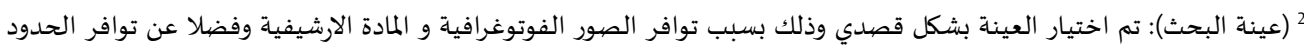
الموضوعية للبحث. 
محمود جباري حسافظ

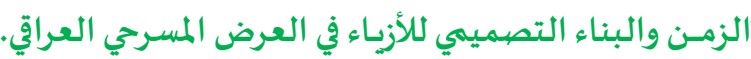

ISSN(Online) 2523-2029, ISSN(Print) 1819-5229 2020 مجلة الأكاديمي-العدد 95-السناء الابيض و الاسود ، فضلا عن تناقضهما اللوني ،وجاء الفستان ليعبر عن الواقع الحقيقي الذي يعيشانه

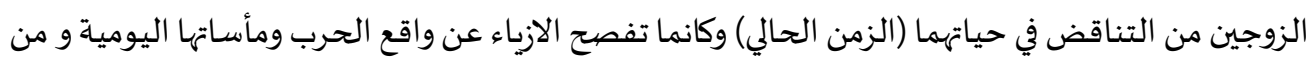

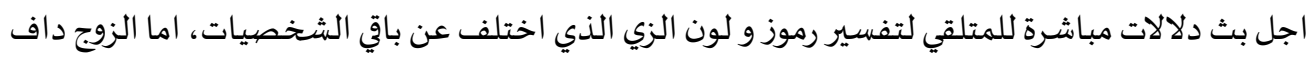

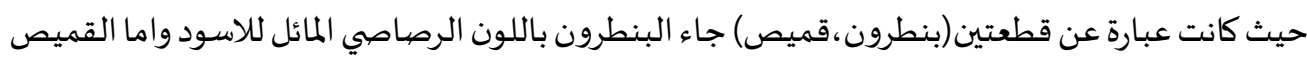
جاء باللون الابيض مع ربطة عنق باللون الرصاصي ايضا ،وهذه ازياء واقعية فيها المزج مابين لونيين

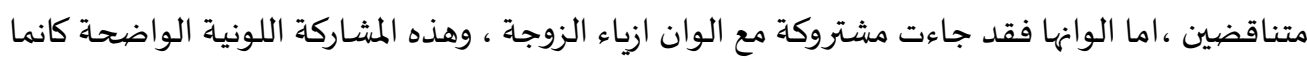

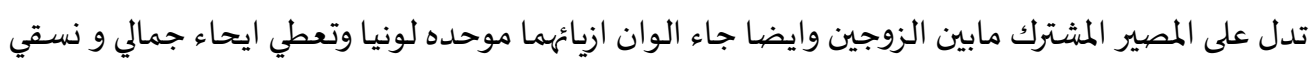

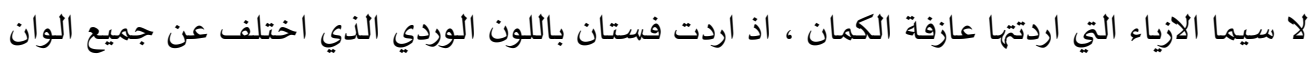

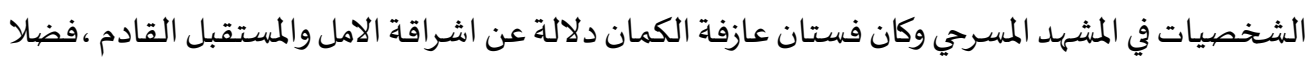
عن اعطاه بصيص امل و التامل في ايجاد المخلص الذي ينتظرانه ، اذ يعبر اللون الوردي دلاليا عن(الامل،والتفاؤل،والاحلام).

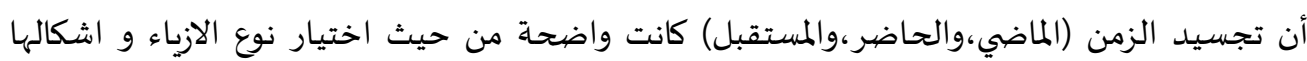

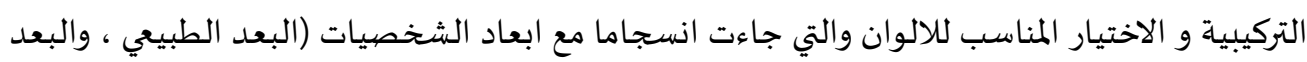

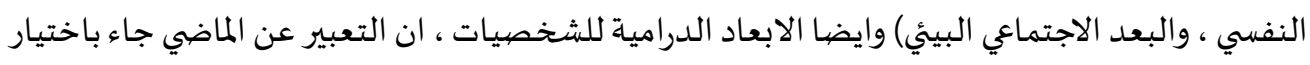

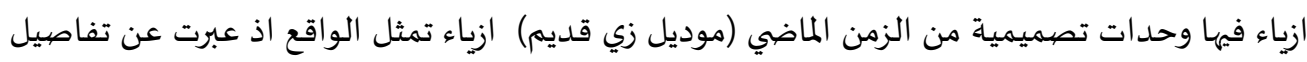

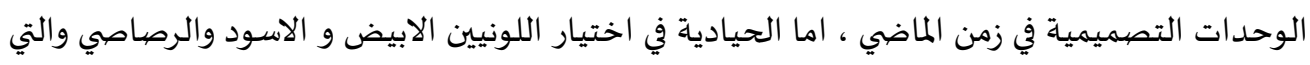

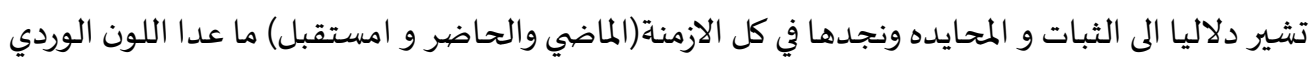

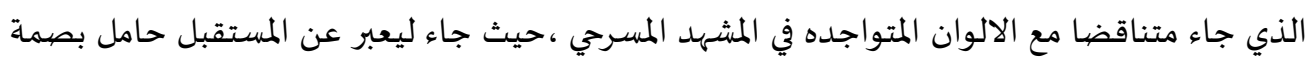

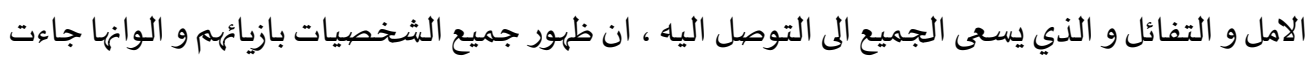

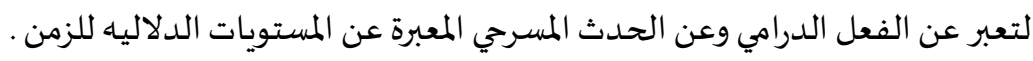
النتائج و الاستنتاجات اولا__النتائج ومناقشتها : الإنجات 1_ ان ادراك الزمن ومستوياته الثلاث (الماضي،والحاضر،والمستقبل) بوساطة العناصر الصورية ومنها الزي

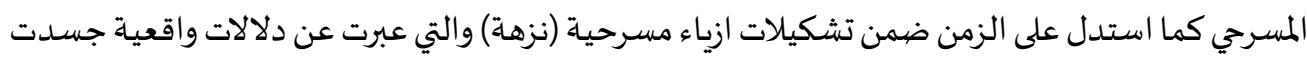
ملامح الزمن وافصحت عنه بشكل واضح . 2_ أن الانتقاله الى الزمن دلاليا عن طريق البناء التصميمي للزي المسرحي ينتج عنه التأمل الحدثي (الزمني

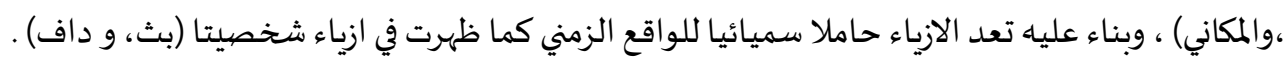

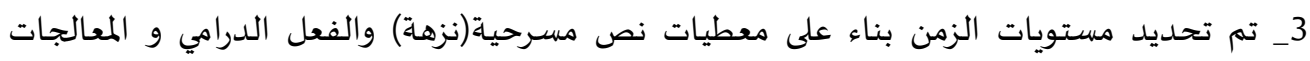

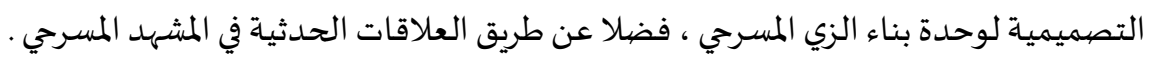

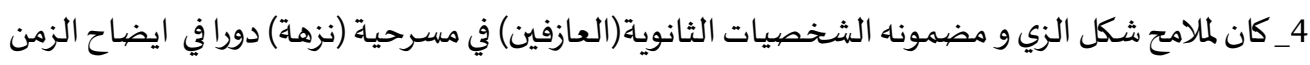

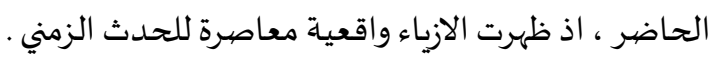


محمدود جباري حافظ

ISSN(Online) 2523-2029, ISSN(Print) 1819-5229 2020 مجلة الأكاديمي-العدد 95-السنة

5_ ان للابعاد الطبيعية و الاجتماعية و النفسية لشخصيات المسرحية(نزهة) انعكاساتها المظهرية عن طريق

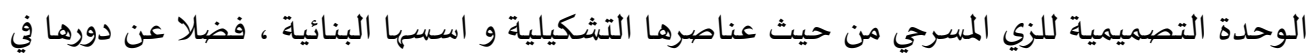
تحديد الزمن و دلالاته . ت الزان.

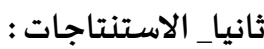
1_ أن ثلاثية مستويات الزمن (الماضي،والحاضر،،والمستقبل) يمكن معرفتها و الاستدلال عليها عن طريق الجانب الصهوري وإيحاءات عناصر العرض المسرحي ومنها عنصر الزي المسرحي كونه يمثل الجانب المرئي

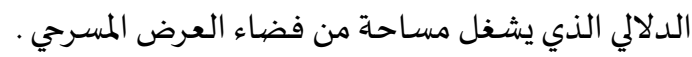

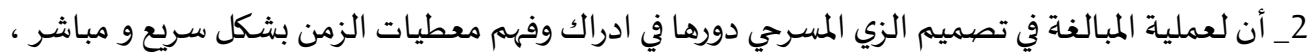
فضلا عن تحديد مفهوم الزمن جماليا وفلسفيا .

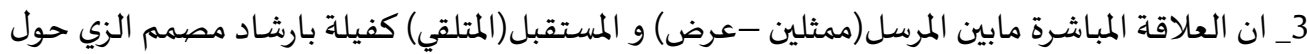

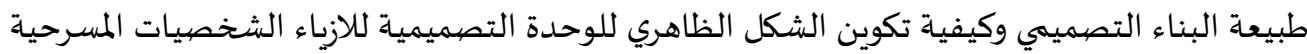

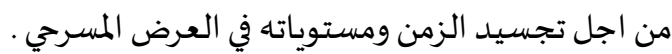
4_ أن للتطور التقني(التكنولوجي) والفني(المساحة الفنية ) في تشكيل عناصر العرض المنسيد المسرحي ومن بينها الازياء المسرحية يساعد في الارتقاء بالجانب الصوري الى مستويات جمالية و ابداعية ، ويساهم في تشكيل

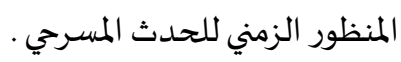

\section{Refences:}

1_ Baristos,jose :Luis Neighbor Drama and Tim, Translated by Talia shaheen ,Translated by Talia shaheen, Egypt ministry of culture Cairo international Festival of Experimental Tester, 2008.

2_Bachalar,Gaston: Dialectic of Time, Translated by Ahmed Khalil,Beirut University Foundation Studies and published by betty Healable, Sufi .

3_Al_Hayat Continuation and Thud Baghdad Iraqi Scientific Society,2000.

4_ Haabeb,Bassma Mohammed: Allocate the evolution of the philosophical understanding of the concept of time, Baghdad, Al-Sabah Newspaper (831) May $11,2006$.

5_AL- Razi , Mohammed Ibn Bakr Abdul Qader: Mukhter AL-Sahah,Kuwait:Dar AL- Resale, 1982.

6_AL_Zayed,Abdul Samad: The Concept of Time and its Significance in the Contemporary Arabic Novel Tunis : 1988 .

7_ The Relation is hip of the presentation_Text Translated by Omar Hails Morocco: Alkali Al-Maghribia newspaper (180), Year(22),1993.

8_Al_Shahan,Ahmed MOhammed:Languaqe of Time and has implications in the Arab Heritage ,Baghdad: General cultural Affairs House, 2000 .

9_AL_Sayegh,Abd: The God of Time by the Arab poets be fore is lam, AL_Rasheed prayers,gamil philosophical Dictionary, Vole 1 Beirut: Lebanese Book House 1982. 
محمـود جباري حافظ الزمسن والبناء التصهميهي للأزـاء في العرض المسرحي العراقي.

ISSN(Online) 2523-2029, ISSN(Print) 1819-5229

مجلة الأكاديمي-العدد 95-السنة 2020

10_Brayers,gamil:Philosophical Dictionary Vole 1 .Beirut: Lebanese Book House 1982 .

11_Said, Glossary of contemn porary Literacy Term in ology , Beirut: Lebanese Book House 1985.

12_Ghazwan, Inad:Echoes of literacy and critical studies, Damascus Arab writers union,2000 .

13_Verduni,Mario: Fashions and Fashion in the film, translated by Tasha Fawzi,cairo General for authoring translation Publishing and bit.P.T

14_Martin,Harsol Sedan: language translation sad macaw cariro:the Egyptian FOundation and the prophets publishing, 1996 .

15_Mir Moon,Har:Time in Literature, translated by Assad Rizk,cairo Franklin Foundation For printing and publishing and, 1972 .

16_King,Haider Lazam:Time and place in the poetry of Abu Toyed mutanabi,doctoral thesis through a publication and after the University of Baghdad College of Arts ,1991 .

17_Mahdi,Shafiq out Theatrical performance Amtrak ph.D.unpublished Qabagdad universe sity of Baghdad College of fine Arts 1996.

18_Buraqi,Samahi:Relation ship between television production and managed(a study in the concept and document) A cadmic gournal,Univer sty of Baghdad College of Arts Campaign Count 62,2012 .

12_Ghazwan,Inad:Echoes of literacy and critical studies, Damascus Arab writers union,2000 .

13_Verduni,Mario: Fashions and Fashion in the film, translated by Tasha Fawzi,cairo General for authoring translation Publishing and bit .P.T

14_Martin,Harsol Sedan: language translation sad macaw cariro:the Egyptian FOundation and the prophets publishing, 1996 .

15_Mir Moon,Har:Time in Literature, translated by Assad Rizk,cairo Franklin Foundation For printing and publishing and, 1972 .

16_King,Haider Lazam:Time and place in the poetry of Abu Toyed mutanabi,doctoral thesis through a publication and after the University of Baghdad College of Arts ,1991 .

17_Mahdi,Shafiq out Theatrical performance Amtrak ph.D.unpublished Qabagdad universe sity of Baghdad College of fine Arts 1996 .

18_Buraqi,Samahi:Relation ship between television production and managed(a study in the concept and document) A cadmic gournal,Univer sty of Baghdad College of Arts Campaign Count 62,2012 . 
محمود جبـاري حافظ الزمسن والبناء التصبميهي للأزيـاء في العرض المسرحي العراقي.

ISSN(Online) 2523-2029, ISSN(Print) 1819-5229

مجلة الأكاديمي-العدد 95-السنة 2020

DOI: https://doi.org/10.35560/jcofarts95/35-48

\title{
Time and Design Construction for Costumes in the Iraqi
} Theater Show

\section{Mahmoud Jabari Hafed ${ }^{1}$}

Al-academy Journal Issue 95 - year 2020 Date of receipt: 7/5/2018........Date of acceptance: 24/6/2018........Date of publication: $15 / 3 / 2020$ (c) (7)

\begin{abstract}
:
The theatre costume with the rest of the theatre show elements constitute a system of the meaning relations that produce a visual image that helps the recipient to decipher the theatre scene, let alone the manifestation of time in its levels (past, present, future) through the design construction of the theatre elements among which is the theatre costume. In order to know the way of manifesting time through the formulation of the theatre costumes, the research question has been put as follows: how to manifest time through the design construction for the theatre costumes unit, from which the research objective is derived as follows: Revealing the possibility of the designing unit of the costumes in manifesting the levels of time within the scenes of the theatre show. The research is divided into four chapters. The first (methodology) and the second (theoretical framework), and the third (procedures) in which a deliberate sample has been chosen, the play (picnic). The fourth chapter presents the research results and discussion as well as the conclusions and a list of sources.
\end{abstract}

Key words: Time, fashion.

\footnotetext{
${ }^{1}$ Assistant Professor Dr. / College of Fine Arts / University of Baghdad, dr.mahmood@avic.uobaghdad.edu.iq.
} 